\title{
Research Article Optimal Control of Production and Remanufacturing in a Reverse Logistics Model with Backlogging
}

\author{
I. Konstantaras ${ }^{1,2}$ \\ ${ }^{1}$ Department of Business Administration, University of Macedonia, 54006 Thessaloniki, Greece \\ ${ }^{2}$ Department of Mathematics, University of Ioannina, 45110 Ioannina, Greece
}

Correspondence should be addressed to I. Konstantaras, ikonst@cc.uoi.gr

Received 24 June 2010; Revised 8 September 2010; Accepted 15 September 2010

Academic Editor: G. Rega

Copyright ( 2010 I. Konstantaras. This is an open access article distributed under the Creative Commons Attribution License, which permits unrestricted use, distribution, and reproduction in any medium, provided the original work is properly cited.

\begin{abstract}
Reverse logistics activities have received increasing attention within logistics and operations management during the last years, both from a theoretical and a practical point of view. The field of reverse logistics includes all logistics processes starting with the take-back of used products from customers up to the stage of making them reusable products or disposing them. In this paper, a single-product recovery system is studied. In such system, used products are collected from customers and are kept at the recoverable inventory warehouse in view to be recovered. The constant demand rate can be satisfied either by newly produced products or by recovered ones (serviceable inventory), which are regarded as perfectly as the new ones. Excess demand is completely backlogged. Following an exact analytical approach, the optimal set-up numbers and the optimal lot sizes for the production of new products and for the recovery of returned products are obtained. A numerical cost comparison of this model with the corresponding one without backordering is also performed.
\end{abstract}

\section{Introduction}

In the classical logistics systems, the main concern is the management flow of raw materials, final products, and related information until the products are delivered to the final customer. The field of reverse logistics contains all logistics processes beginning with the take-back of used products from customers up to the stage of making them reusable products or disposing them. Reverse logistics activities have received increasing attention within logistics and operations management during the last years, both from a theoretical and a practical point of view. One reason for this is the more rigid environmental legislations and the 
growing environmental concerns. Yet one more reason is the awakening to the economical attractiveness of reusing products rather than disposing them.

There are four main steps in the reverse logistic process; see the work by de Brito in [1]. The first step is the collection of used products. The next step is the combined inspection and sorting processes. These are followed by the reprocessing or direct recovery step of used products, and the cycle closes with the redistribution step. Collection deals with bringing the used products from customers to a collection recovery point. This point may be the company itself or other companies in the business chain or companies outside the business chain; see the work by Thierry et al. in [2]. At the collection point, used products are inspected, their quality status is assessed, and a decision is made on the type of recovery process they will undergo. There are different types of recovery: repair, refurbishing, remanufacturing, cannibalization, and recycling; see the work by Thierry et al. in [2]. Repair brings used products to working status. Refurbishing brings used products up to a specified quality level and extends their service life. Remanufacturing brings used products up to quality standards that are as rigorous as those for new products. The cannibalization is to recover a limited set of reusable parts, and recycling is to extract materials from used products and components in view to reuse them. Redistribution is the process of bringing the recovered products to new end-user customers.

In a system with repair, remanufacturing, or refurbishing, recovery is an alternative to manufacturing. The supplier meets the demand for a product and receives used products returned from customers. Returned products are stocked at the recoverable inventory warehouse and create the stock of recoverable products. The supplier has two alternatives to fulfill the demand: either he orders externally / produces new items or recovers used products and brings them back to "as new" condition. Note that since recovered (remanufactured) items have the same quality as manufactured items and are sold for the same price in the same market, there is no need to distinguish between the two. Both types are serviceable and are used to satisfy the same customer demands. Clearly, in order to control such a system efficiently, manufacturing and remanufacturing decisions have to be coordinated. There has been a considerable number of contributions dealing with inventory control for joint manufacturing and remanufacturing. Two very good reviews on quantitative models for recovery production planning and inventory control are given in the work by Fleischmann et al. in [3] and that by Guide Jr. and Srivastava in [4].

Several authors have studied recovery systems using the Economic Ordering Quantity (EOQ) technique. The main advantage of EOQ models is that, due to their simplicity, they lead to closed-form expressions for the optimal lot sizes. Schrady [5] was the first who analyzed an EOQ model with recovery. He analyzed the problem assuming constant demand and return rates and infinite production and recovery rates. He considered policies that alternate one production lot with a variable number of recovery lots. The model's objective was to minimize the total cost per unit of time for placing orders and holding inventory. In this class of policies, the optimal lot sizes for production and recovery were given and their expressions are similar to the EOQ formula. Nahmias and Rivera [6] studied a deterministic model, similar to that of Schrady, but with a finite recovery rate greater than demand rate. An extension of Schrady's model has been proposed by Mabini et al. [7]. They consider a singleitem model, allowing stockouts up to a certain level and a multi-item one, without stockouts, where all items share the same repair facility. A generalization to Nahmias and Rivera's [6] model was proposed by Koh et al. [8]. These authors assumed a limited repair capacity and examined the cases where the recovery rate is smaller or larger than the demand rate. Richter [9-11] and Richter and Dobos [12,13] proposed an EOQ model that differs from Schrady's 
model, where it has a waste disposal option with the return rate of used items being a decision variable. In these works, the optimal numbers of remanufacturing and production batches in an interval of time were dependent on the return rate. Dobos and Richter [14] investigated the characteristics of the cost function developed in a previous work [12], where they showed that the cost is partly piecewise convex and partly piecewise concave function of the waste disposal rate. In a follow-up paper, Dobos and Richter [15] presented a generalization of their earlier work [14] by assuming a time interval to contain multiple repair and multiple production cycles. Dobos and Richter [16] investigated the production-recycling model in Dobos and Richter [15] by considering that the quality of collected used items (returns) is not always suitable for recycling.

Along the same line of research, Teunter [17] generalized Schrady's results by considering $\mathrm{M}$ manufacturing (production) lots of equal size and $\mathrm{R}$ recovery (remanufacturing) lots of equal size (in short (M, R) policy) and assuming the holding cost for recoverable items to be different from that of recovered and manufactured items. In another work, Teunter [18] relaxed the assumption of an instantaneous manufacturing and remanufacturing process in order to derive more general expressions for the manufacturing and remanufacturing lot sizes. Choi et al. [19] generalized the (M, R) policy proposed by Teunter [17] by relaxing the assumption on the disposal of used items and treating the sequence of manufacturing and remanufacturing setups in a cycle as a decision variable. Their sensitivity analysis showed that using the (M, R) policy, only $0.2 \%$ out of $8,100,000$ tested problems have an optimal solution in which both $\mathrm{M}$ and $\mathrm{R}$ are greater than one. This indicates that with a maximum deviation of $0.2 \%$ from the optimal solution, one may as well use $(1, R)$ or $(M, 1)$ policy rather than the $(\mathrm{M}, \mathrm{R})$ policy. Other researchers have also developed models along the same lines as Schrady, Richter, and Teunter, but with different assumptions [20-24].

All above articles are EOQ models with deterministic constant demand and returns. The determination of an optimal continuous control policy in a situation with deterministic but dynamic demands and returns is the subject of the paper by Minner and Kleber [25]. An extension to the previous paper is the paper by Kiesmüller et al. [26]. They considered that backlogging is possible and showed that in recovery systems, backlogging is not only something which has to be avoided, but is also a mean for improving the performance of the system.

In this paper, we extend the models proposed by Koh et al. [8] and Nahmias and Rivera [6], by allowing backlogging and finite production and recovery rates. The so-created three new models are studied in the case where production and recovery rates are greater than the demand rate, which in turn is greater than the return rate. Demand at the beginning of the horizon and up to the moment at which the first remanufacturing cycle starts is satisfied by newly produced items, and during this period we allow complete backlogging of the excess demand. For each of the three models, we determine the optimal policy, which specifies the number of manufacturing and remanufacturing setup and the corresponding lot sizes. Further, computational results referring to the cost efficiency of the three models are reported.

The paper is organized as follows. The assumptions, notation, and the description of the models are given in Section 2. Section 3 is devoted to searching for optimality within the set of policies with exactly one recovery setup and at least one production setup. The reverse situation under Koh's approach is investigated in Section 4. The fifth section is devoted to searching for optimality within the set of policies with exactly one production setup and at least one recovery setup under Nahmias's approach. The Koh's and Nahmias' approaches differ only in relation to the time at which the recovery process starts. In Nahmias' approach, 
recovery is postponed until the stock of serviceable items drops to zero, while in Koh's approach, the recovery starts as soon as the stock of recoverable items reaches a certain level which has to be determined (decision variable). The sixth section contains a numerical example, which illustrates the application of all results presented in the article. The article closes with Section 7, where we summarize the obtained results and propose topics for further research.

\section{Model Description and Notation}

The model, which is studied in this paper, is a combination of single-product recovery system and of a production/manufacturing system and is developed under the following assumptions.

(i) The planning horizon of the system is infinite.

(ii) The system stocks a single product, facing a fixed demand rate of $d$ units, which may be satisfied either by newly produced products or by used ones which have been remanufactured.

(iii) Used products are returned at a fixed rate $r$ and are stored in the used products warehouse (recoverable inventory).

(iv) At some time $t$, the recovery process starts, with a fixed rate of $p$ units and continues until the recoverable inventory goes down to zero. All returned products are remanufactured.

(v) The recovered (remanufactured) products are transferred into the warehouse, where the stock of new produced items is also kept. New and recovered products constitute the so-called stock of serviceable, and demand is satisfied by them.

(vi) Shortages are allowed at the production stage and are fully backlogged.

(vii) Production, recovery, demand, and return rates are such that $s, p>d>r$.

The complete list of the notation, which is used in this paper, is

$Q_{p}$ : production lot size

$Q_{r}$ : recovery lot size

$V$ : maximum inventory level of serviceable products

$U$ : inventory level (maximum) of used products, at the time that the recovery process starts

$n_{1}$ : number of setups at the recovery shop

$n_{2}$ : number of orders for new products

$T$ : cycle time of model

$t$ : idle time interval of the recovery process

$d$ : constant demand rate for the product

$r$ : constant return rate

$p$ : recovery rate

$s$ : production rate 
$R$ : fixed set-up cost for the recovery process

$S$ : fixed ordering (set-up) cost per production lot

$h$ : inventory holding cost for the used (recoverable) items

$H$ : inventory holding cost for serviceable items

$B$ : shortages cost for serviceable items

$x$ : duration of serviceable inventory cycle when stock-out condition exists and manufacturing switches on

$y$ : duration of serviceable inventory cycle when there is positive inventory and manufacturing switches on

$P\left(n_{1}, n_{2}\right)$ : the set of policies with $n_{1}$ setup in the recovery shop and $n_{2}$ orders for new products.

The number of setup taken in the recovery and the production/manufacturing shop during the cycle characterizes the policies used to control such systems. In this paper, we do not consider all possible policies, but restrict attention to two classes: (i) the set of $P\left(1, n_{2}\right)$ policies where one setup in the recovery shop alternates with a variable number $n_{2}$ of production/manufacturing lots for new products (in a cycle), (ii) the set of $P\left(n_{1}, 1\right)$ policies where one production lot for new products alternates with a variable number $n_{1}$ of recovery lots.

\section{Modeling in the Set of Policies $P\left(1, n_{2}\right)$ \\ (One Recovery, Variable Number of Production Setup)}

In this section, we model the case which alternates one setup in the recovery shop with a variable number $n_{2}$ of production setup for new items. For this case, we find the optimal lot sizes for the production of new and for the recovery of returned products and also the optimal number of production setup.

The evolution of inventory stock levels under such a policy is depicted in Figure 1.The upper part of this figure shows the evolution of the recoverable stock while the lower part gives the evolution of the serviceable inventory. Let $t_{p}$ be the length of time over which the replenishment takes place at the rate $s$. By the end of this period, the lot size $Q_{p}$ will have been added to the serviceable stock. Hence,

$$
t_{p}=\frac{Q_{p}}{S} .
$$

Since the serviceable inventory rises along the line $A D$ at a rate of $s-d$, we have

$$
\overline{E D}=(s-d) t_{p}=\frac{(s-d) Q_{p}}{s} .
$$

From Figure 2, we see that

$$
\overline{E F}=\overline{A B}-V=Q_{p}-V,
$$




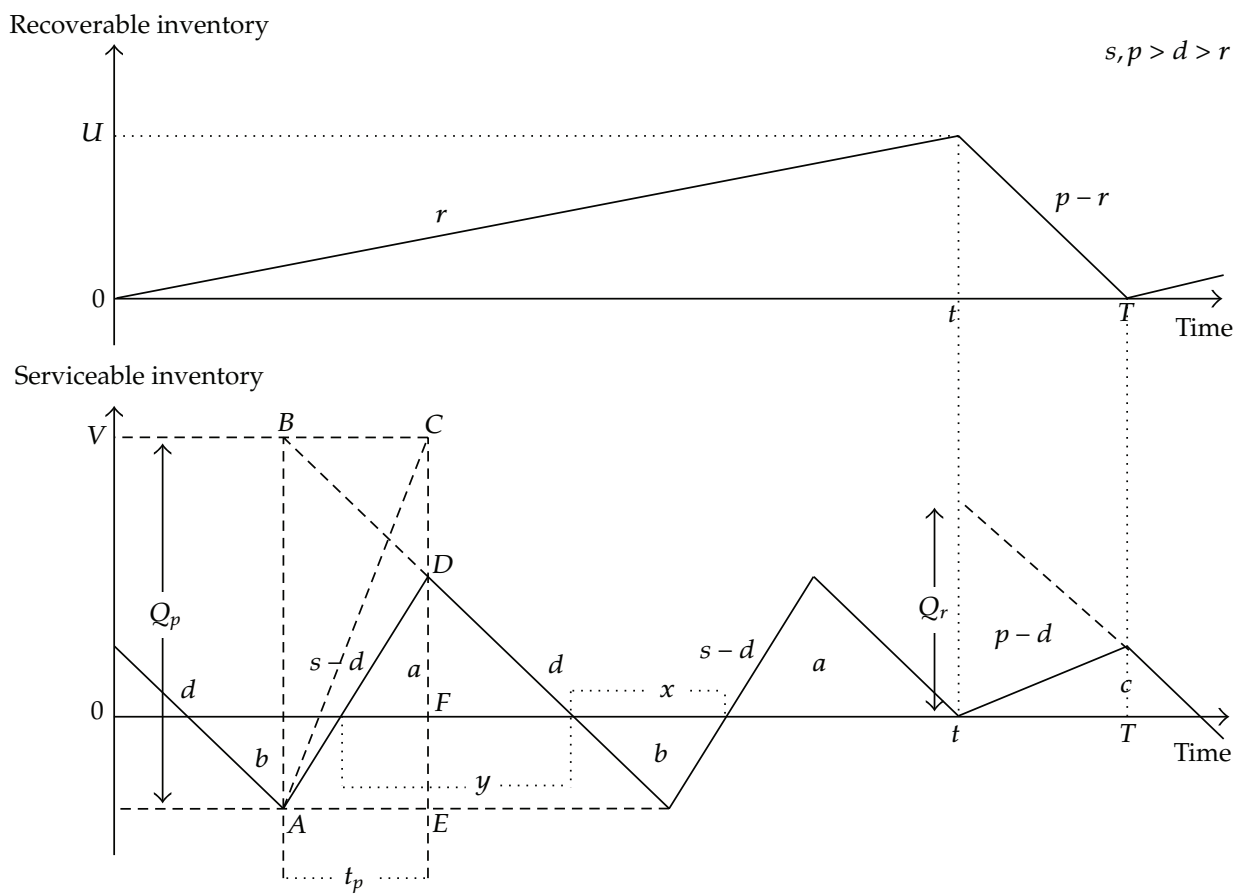

Figure 1: One or more production setup for one recovery setup.

and from (3.2) and (3.3), we take

$$
\overline{F D}=\overline{E D}-\overline{E F}=V-\frac{d Q_{p}}{s} .
$$

From the upper graph of Figure 2, we can easily see that $t=U / r, T-t=U /(p-r)$ and so

$$
T=\frac{U}{p-r}+\frac{U}{r}=\frac{p}{p-r} t
$$

From the lower graph of Figure 2, we can find that

$$
t=n_{2}(x+y)+\frac{(p-d)(T-t)}{d}=n_{2}(x+y)+\frac{r(p-d) t}{d(p-r)} \Longrightarrow t=\frac{d(p-r) n_{2}(x+y)}{p(d-r)}
$$

Substituting $t$ from (3.6) into (3.5) yields

$$
T=\frac{d n_{2}(x+y)}{d-r} .
$$


The per-cycle cost related to recoverable inventory consists of the recovery set-up cost and the holding cost of used items. One can easily show that this cost is

$$
R+\frac{h U t}{2}+\frac{h U(T-t)}{2}=R+\frac{h U T}{2}
$$

The per-cycle cost for serviceable products consists of the following four components:

(i) ordering cost for $n_{2}$ production lots, $n_{2} S$,

(ii) inventory holding cost for $n_{2}$ triangles of type (a) in Figure 2,

$$
\frac{n_{2} H y \overline{F D}}{2}=\frac{n_{2} H d(s-d) y^{2}}{2 s}
$$

(iii) backordering cost for $n_{2}$ triangles of type (b) in Figure 2,

$$
\frac{n_{2} B\left(Q_{p}-V\right) x}{2}=\frac{n_{2} B d(s-d) x^{2}}{2 s}
$$

(iv) inventory holding cost for triangle of type (c) in Figure 2,

$$
\frac{H(p-d)(T-t)(T-t+(p-d)(T-t) / d)}{2}=\frac{H d(p-d) r^{2} n_{2}^{2}(x+y)^{2}}{2 p(d-r)^{2}} .
$$

The total cost per cycle is

$$
\mathrm{TC}\left(x, y, n_{2}\right)=R+\frac{h U T}{2}+n_{2} S+\frac{n_{2} H d(s-d) y^{2}}{2 s}+\frac{H d(p-d) r^{2} n_{2}^{2}(x+y)^{2}}{2 p(d-r)^{2}}+\frac{n_{2} B d(s-d) x^{2}}{2 s}
$$

and dividing by the cycle length $T=d n_{2}(x+y) /(d-r)$, we obtain the total cost per unit of time

$$
\begin{aligned}
\operatorname{UTC}\left(x, y, n_{2}\right)= & \frac{R(d-r)}{d n_{2}(x+y)}+\frac{S(d-r)}{d(x+y)}+\frac{h r d(p-r) n_{2}(x+y)}{2 p(d-r)} \\
& +\frac{H(s-d)(d-r) y^{2}}{2 s(x+y)}+\frac{H r^{2}(p-d) n_{2}(x+y)}{2 p(d-r)}+\frac{B(s-d)(d-r) x^{2}}{2 s(x+y)}
\end{aligned}
$$

In the above expression, we replace $y$ through the transformation $x /(x+y)=k$, and (3.13) 
becomes

$$
\mathrm{UTC}\left(x, k, n_{2}\right)=c_{1} \frac{k}{x}+c_{2} \frac{x}{k}+c_{3} x k-c_{4} x, \quad x \in(0, \infty), k \in(0,1], n_{2}=1,2,3, \ldots,
$$

where

$$
\begin{gathered}
c_{1}=\frac{R(d-r)}{d n_{2}}+\frac{S(d-r)}{d}>0, \\
c_{2}=\frac{n_{2} d(p-r) r h}{2 p(d-r)}+\frac{n_{2} r^{2}(p-d) H}{2 p(d-r)}+\frac{(s-d)(d-r) H}{2 s}>0, \\
c_{3}=\frac{(s-d)(d-r)(H+B)}{2 s}>0, \\
c_{4}=\frac{(s-d)(d-r) H}{s}>0 .
\end{gathered}
$$

The problem now is

$$
\min _{x, k, n_{2}} \operatorname{UTC}\left(x, k, n_{2}\right)
$$

To solve this, we proceed as follows. First, we find the minimum of UTC $\left(x, k, n_{2}\right)$ with respect to $x, k$. The minimizing point is a function of $n_{2}$, say $\left\{x\left(n_{2}\right), k\left(n_{2}\right)\right\}$. Next, we substitute it into the objective function which now becomes a function only of $n_{2}$ and minimize with respect to $n_{2}$. Setting the partial derivates of $\operatorname{UTC}\left(x, k, n_{2}\right)$, with respect to $k$ and $x$, equal to zero, we have

$$
\begin{aligned}
& \frac{\partial \mathrm{UTC}\left(x, k, n_{2}\right)}{\partial k}=\frac{c_{1}}{x}-\frac{c_{2} x}{k^{2}}+c_{3} x=0 \\
& \frac{\partial \mathrm{UTC}\left(x, k, n_{2}\right)}{\partial x}=-\frac{c_{1} k}{x^{2}}+\frac{c_{2}}{k}+c_{3} k-c_{4}=0 .
\end{aligned}
$$

The unique solution of this system is

$$
\begin{gathered}
k^{*}=\frac{c_{4}}{2 c_{3}}=\frac{H}{H+B^{\prime}}, \\
x^{*}=c_{4} \sqrt{\frac{c_{1}}{c_{3}\left(4 c_{2} c_{3}-c_{4}{ }^{2}\right)}} .
\end{gathered}
$$

It is easy to prove (see the appendix) that the point $\left(k^{*}, x^{*}\right)$ satisfies the second-order conditions for the minimum of UTC $\left(x, k, n_{2}\right)$. Substituting $k^{*}$ and $x^{*}$ into (3.14), we obtain

$$
\operatorname{UTC}\left(x^{*}, k^{*}, n_{2}\right)=f\left(n_{2}\right)=\sqrt{\frac{c_{1}\left(4 c_{2} c_{3}-c_{4}^{2}\right)}{c_{3}}}=\sqrt{b_{1} a_{1}+b_{2} a_{2}+a_{1} b_{2} n_{2}+\frac{b_{1} a_{2}}{n_{2}}},
$$


where

$$
\begin{gathered}
a_{1}=\frac{(s-d) r[d(p-r) h+r(p-d) H](H+B)}{p s}>0, \\
a_{2}=\frac{(s-d)^{2}(d-r)^{2} H B}{s^{2}}>0, \\
b_{1}=\frac{2 s R}{d(s-d)(B+H)}>0, \\
b_{2}=\frac{2 s S}{d(d-s)(B+H)}>0, \\
L=4 c_{2} c_{3}-c_{4}^{2}=a_{1} n_{2}+a_{2}>0 .
\end{gathered}
$$

Since $n_{2}$ is integer, to locate the optimal $n_{2}$, we use the difference function

$$
\Delta f\left(n_{2}\right)=f\left(n_{2}\right)-f\left(n_{2}-1\right), \quad n_{2} \geq 2
$$

which in our case is

$$
\begin{aligned}
\Delta f\left(n_{2}\right) & =f\left(n_{2}\right)-f\left(n_{2}-1\right) \\
& =\frac{b_{2} a_{1}-\left(b_{1} a_{2}\right) / n_{2}\left(n_{2}-1\right)}{\sqrt{b_{1} a_{1}+b_{2} a_{2}+a_{1} b_{2} n_{2}+b_{1} a_{2} / n_{2}}+\sqrt{b_{1} a_{1}+b_{2} a_{2}+a_{1} b_{2}\left(n_{2}-1\right)+b_{1} a_{2} /\left(n_{2}-1\right)}} .
\end{aligned}
$$

From (3.22), we see that if $b_{1} a_{2} / b_{2} a_{1} \leq 2$, then $\Delta f\left(n_{2}\right) \geq 0$ for all $n_{2} \geq 2$ and the optimum is $n_{2}^{*}=1$.

If this is not the case, then there always exists a $n_{2}^{*} \geq 2$ such that $\Delta f\left(n_{2}\right)<0$ for all $n_{2} \leq n_{2}^{*}$ and $\Delta f\left(n_{2}\right) \geq 0$ for all $n_{2}>n_{2}^{*}$. Simple algebra on these inequalities gives that this $n_{2}$ satisfies the double inequality

$$
n_{2}^{*}\left(n_{2}^{*}-1\right)<\frac{a_{2} b_{1}}{a_{1} b_{2}} \leq n_{2}^{*}\left(n_{2}^{*}+1\right), \quad n_{2}^{*} \geq 2
$$

In the case that $n_{2}^{*}\left(n_{2}^{*}+1\right)=a_{2} b_{1} / a_{1} b_{2}$, we have two equivalent solutions (same cost). The integer value of $n_{2}^{*}$ obtained from (3.23) is used in (3.15), (3.18), and (3.19) to calculate $c_{1}$, $c_{2}, c_{3}, c_{4}, x^{*}, k^{*}, \mathrm{UTC}\left(x^{*}, k^{*}, n_{2}\right)$ and the resulting policy can be implemented to give the minimum cost. The optimal lot sizes for this class of policies are

$$
\begin{gathered}
Q_{p}=d\left(x^{*}+y^{*}\right), \\
Q_{r}=\frac{d r n_{2}^{*}\left(x^{*}+y^{*}\right)}{d-r},
\end{gathered}
$$

where $y^{*}=\left(1-k^{*}\right) x^{*} / k^{*}$. 


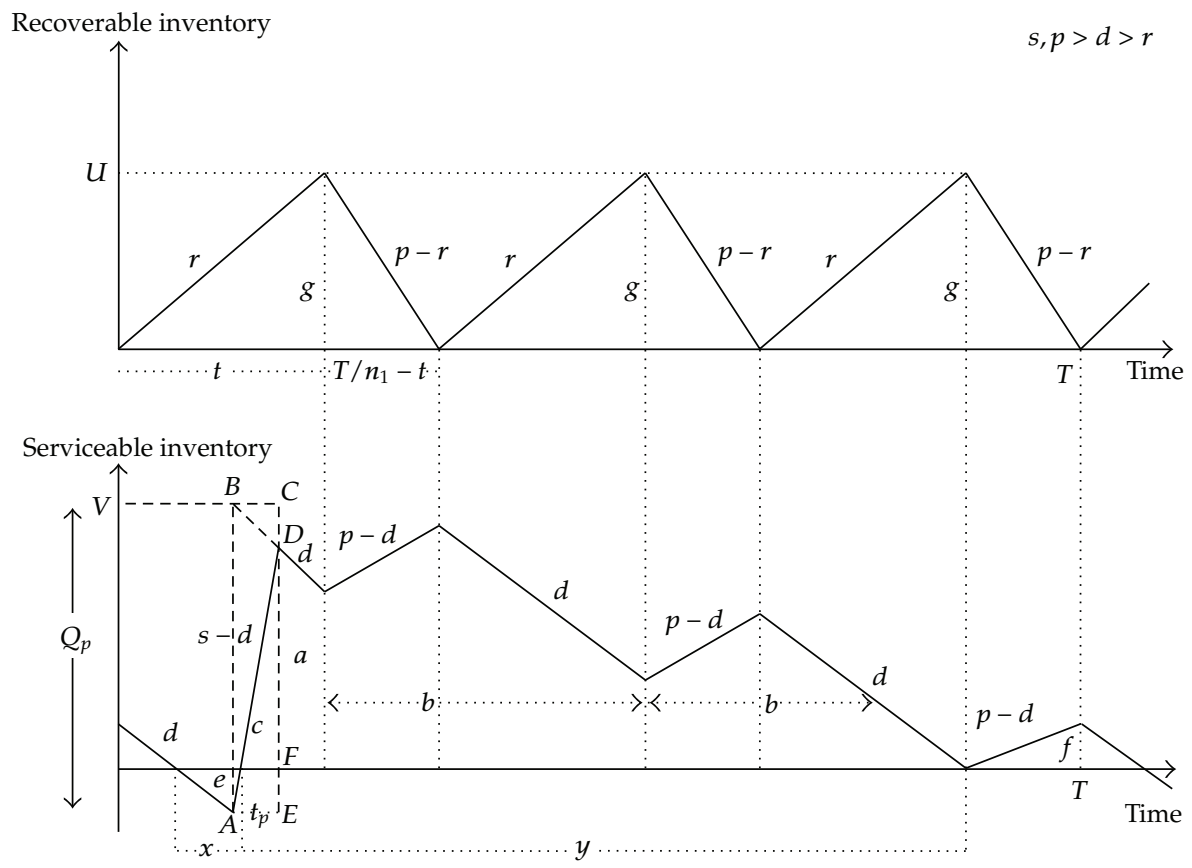

Figure 2: One or more recovery setup for a production setup under Koh's approach.

\section{Modeling in the Set $P\left(n_{1}, 1\right)$ (Variable Recovery Opportunities, One Production Lot) under Koh's Approach}

In this section, we model the case which alternates one production setup for new products with a variable number $n_{1}$ of recovery lots under Koh's et al. [8] approach. Koh's approach calls for recovery as soon as the stock of recoverable items reaches a certain level which has to be determined (decision variable). For this case, we find the optimal lot sizes for the production of new and for the recovery of returned products and also the optimal number of remanufacturing setup.

The upper part of Figure 2 shows the evolution of the recoverable stock while the lower part of this figure gives the evolution of the serviceable inventory. The per-cycle cost related to recoverable inventory consists of the recovery setup cost and the holding cost. One can easily show that this is

$$
n_{1} R+n_{1} \frac{h U T}{2 n_{1}}=n_{1} R+\frac{h U T}{2} .
$$

The per-cycle cost for serviceable products consists of the production set-up cost, the inventory holding cost, and the backordering cost. The per-cycle production set-up cost is $S$. The inventory holding cost consists of the following four terms:

(i) inventory holding cost for triangle of type $(f)$ in Figure 3,

$$
\frac{H(p-d)\left(T / n_{1}-t\right)\left(T / n_{1}-t+((p-d) / d)\left(T / n_{1}-t\right)\right)}{2},
$$


(ii) inventory holding cost for trapezoid (a) in Figure 3,

$$
\frac{H\left(2 \overline{F D}-d\left(t-\frac{\overline{F D}}{(s-d)}-x-\frac{(p-d)}{d}\left(\frac{T}{n_{1}}-t\right)\right)\right)\left(t-\frac{\overline{F D}}{(s-d)}-x-\frac{p-d}{d}\left(\frac{T}{n_{1}}-t\right)\right)}{2},
$$

(iii) inventory holding cost for $n_{1}-1$ pentagons of type (b) in Figure 3,

$$
\begin{gathered}
\sum_{i=1}^{n_{1}-1} \frac{H}{2}\left[(2 i-1) d t^{2}+[2 d i-2(i-1)(p-d)]\left(\frac{T}{n_{1}}-t\right) t-(2 i-1)(p-d)\left(\frac{T}{n_{1}}-t\right)^{2}\right] \\
=\frac{H r d^{2}(p-r)\left(n_{1}-1\right)(x+y)^{2}}{2 p\left(n_{1} d-r\right)^{2}}+\frac{H d^{2}(d-r)\left(n_{1}-1\right)^{2}(x+y)^{2}}{2\left(n_{1} d-r\right)^{2}}
\end{gathered}
$$

(iv) inventory holding cost for triangle of type (c) in Figure 3,

$$
\frac{1}{2} H \overline{F D} \frac{\overline{F D}}{s-d}=\frac{H \overline{F D}^{2}}{s-d}
$$

(v) backordering cost for triangle of type (e) in Figure 3,

$$
\frac{B\left(Q_{p}-V\right) x}{2}=\frac{d(s-d) B x^{2}}{2 s}
$$

From the upper graph of Figure 3, we can easily see that

$$
\frac{T}{n_{1}}=t+\left(\frac{T}{n_{1}}-t\right)=\frac{U}{r}+\frac{U}{p-r}=\frac{p}{p-r} t .
$$

Similarly, from the lower graph, we can find that

$$
\begin{gathered}
T=x+y+\frac{(p-d)\left(T / n_{1}-t\right)}{d}+\frac{(p-d)\left(T / n_{1}-t\right)}{p-d} \Longrightarrow t=\frac{d(p-r)(x+y)}{p\left(n_{1} d-r\right)}, \\
\overline{F D}=\frac{s-d}{d}\left(d\left(t-x-\frac{(p-d)\left(T / n_{1}-t\right)}{d}\right)+\left(n_{1}-1\right) d t-\left(n_{1}-1\right)(p-d)\left(\frac{T}{n_{1}}-t\right)\right) .
\end{gathered}
$$


Substituting $t$ from (4.8) into (4.7) and (4.9) yields

$$
\begin{gathered}
T=\frac{d n_{1}(x+y)}{n_{1} d-r}, \\
\overline{F D}=\frac{(s-d)}{s}\left(\frac{n_{1} d(d-r)(x+y)}{n_{1} d-r}-d x\right) .
\end{gathered}
$$

The total cost per unit of time for this case is

$$
\begin{aligned}
\operatorname{UTC}\left(x, y, n_{1}\right)= & \frac{R\left(n_{1} d-r\right)}{d(x+y)}+\frac{S\left(n_{1} d-r\right)}{d n_{1}(x+y)}-\frac{H(s-d)(d-r)}{s} x \\
& +\left[\frac{B(s-d)\left(n_{1} d-r\right)}{2 n_{1} s}+\frac{H\left(n_{1} d-r\right)}{2 n_{1}}-\frac{H d\left(n_{1} d-r\right)}{2 n_{1} s}\right]\left(\frac{x^{2}}{x+y}\right) \\
& +\left[\frac{h r d(p-r)}{2 p\left(n_{1} d-r\right)}+\frac{H r^{2}(p-d)}{2 p\left(n_{1} d-r\right)}+\frac{H(d-r)}{2}-\frac{n_{1} d H(d-r)^{2}}{2 s\left(n_{1} d-r\right)}\right](x+y) .
\end{aligned}
$$

In this function, we again make the transformation $x /(x+y)=k$ and we get the result of

$$
\operatorname{UTC}\left(x, k, n_{1}\right)=c_{1} \frac{k}{x}+c_{2} \frac{x}{k}+c_{3} x k-c_{4} x, \quad x \in(0, \infty), k \in(0,1], n_{1}=1,2,3, \ldots,
$$

where

$$
\begin{gathered}
c_{1}=\frac{R\left(n_{1} d-r\right)}{d}+\frac{S\left(n_{1} d-r\right)}{n_{1} d}>0, \\
c_{2}=\frac{h r d(p-r)}{2 p\left(n_{1} d-r\right)}+\frac{H r^{2}(p-d)}{2 p\left(n_{1} d-r\right)}+\frac{(d-r) H}{2}-\frac{n_{1} d H(d-r)^{2}}{2 s\left(n_{1} d-r\right)}, \\
c_{3}=\frac{(s-d)\left(n_{1} d-r\right)(H+B)}{2 n_{1} s}>0, \\
c_{4}=\frac{(s-d)(d-r) H}{s}>0 .
\end{gathered}
$$

The problem now is

$$
\min _{x, k, n_{1}} \operatorname{UTC}\left(x, k, n_{1}\right)
$$


Following the procedure used in Section 3, we find the optimal values of $k$ and $x$. These values are

$$
\begin{gathered}
k^{*}=\frac{c_{4}}{2 c_{3}}=\frac{n_{1}(d-r) H}{\left(n_{1} d-r\right)(H+B)}, \\
x^{*}=c_{4} \sqrt{\frac{c_{1}}{c_{3}\left(4 c_{2} c_{3}-c_{4}^{2}\right)}} .
\end{gathered}
$$

The Hessian matrix of $\operatorname{UTC}\left(x, k, n_{1}\right)$ at the point $\left(k^{*}, x^{*}\right)$ is positive definite (see the appendix) and so this point gives the minimum. Substituting (4.15) and (4.16) into (4.12) yields

$$
\operatorname{UTC}\left(x^{*}, k^{*}, n_{1}\right)=f\left(n_{1}\right)=\sqrt{\frac{c_{1}\left(4 c_{2} c_{3}-c_{4}^{2}\right)}{c_{3}}}=\sqrt{a_{1} b_{1}+a_{2} b_{2}+a_{2} b_{1} n_{1}+\frac{a_{1} b_{2}}{n_{1}}},
$$

where now

$$
\begin{gathered}
a_{1}=\frac{(s-d) r[d(p-r) h+r(p-d) H-H p(d-r)](H+B)}{s p} \in R, \\
a_{2}=\frac{(s-d)(d-r) H}{s}\left[r H+\frac{d B(s-d+r)}{s}\right]>0, \\
b_{1}=\frac{2 s R}{d(s-d)(B+H)}>0, \\
b_{2}=\frac{2 s S}{d(s-d)(B+H)}>0 .
\end{gathered}
$$

For (4.16) and (4.17) to be meaningful, we assume that $L=4 c_{2} c_{3}-c_{4}^{2}=a_{1} / n_{1}+a_{2}>0$, which seems to be the case in real problems. The difference function is

$$
\begin{aligned}
\Delta f\left(n_{1}\right) & =f\left(n_{1}\right)-f\left(n_{1}-1\right) \\
& =\frac{a_{2} b_{1}-a_{1} b_{2} / n_{1}\left(n_{1}-1\right)}{\sqrt{a_{1} b_{1}+a_{2} b_{2}+a_{2} b_{1} n_{1}+a_{1} b_{2} / n_{1}}+\sqrt{a_{1} b_{1}+a_{2} b_{2}+a_{2} b_{1}\left(n_{1}-1\right)+a_{1} b_{2} /\left(n_{1}-1\right)}} .
\end{aligned}
$$

From (4.19), we see that if $a_{1} \leq 0$ or $a_{1} b_{2} / a_{2} b_{1} \leq 2$, then $\Delta f\left(n_{1}\right) \geq 0$ for any $n_{1} \geq 2$ and the optimum is $n_{1}^{*}=1$. If this is not the case, then the optimal $n_{1}^{*}$ satisfies the double inequality

$$
n_{1}^{*}\left(n_{1}^{*}-1\right)<\frac{a_{1} b_{2}}{a_{2} b_{1}} \leq n_{1}^{*}\left(n_{1}^{*}+1\right), \quad n_{1}^{*} \geq 2
$$




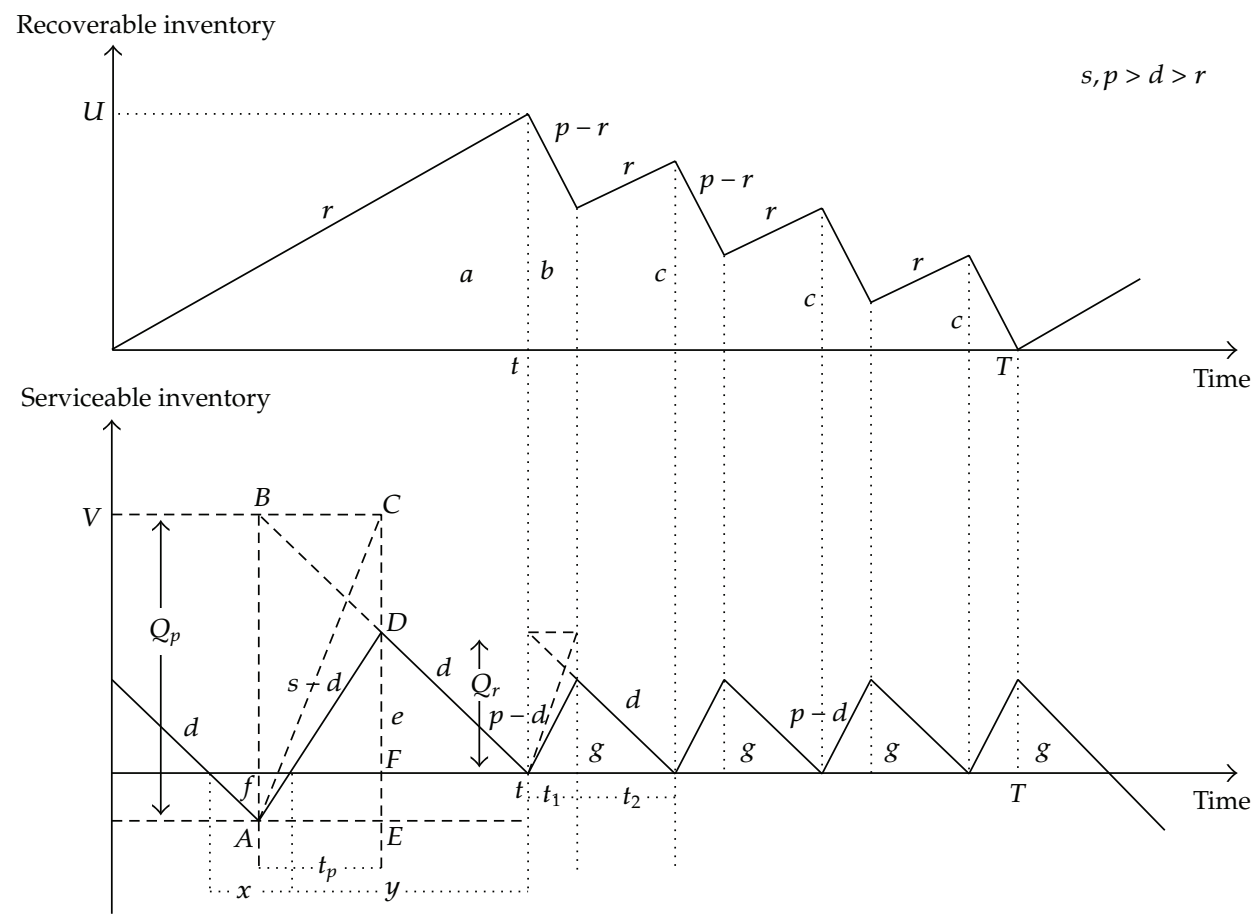

Figure 3: One or more recovery setup for a production setup under Nahmias' approach.

In the case that $n_{1}^{*}\left(n_{1}^{*}+1\right)=a_{1} b_{2} / a_{2} b_{1}$, we have two equivalent solutions (same cost). The optimal lot sizes for this class of policies are

$$
\begin{gathered}
Q_{p}=\frac{n_{1}^{*} d(d-r)\left(x^{*}+y^{*}\right)}{n_{1}^{*} d-r}, \\
Q_{r}=\frac{d r\left(x^{*}+y^{*}\right)}{n_{1}^{*} d-r} .
\end{gathered}
$$

\section{Modeling in the Set $P\left(n_{1}, 1\right)$ (Variable Recovery Opportunities, One Production Lot) under Nahmias' Approach}

In this section, we model the same case as in Section 4 under now Nahmias' [6] approach. Nahmias' approach calls for recovery as soon as the stock of serviceable items drops to zero. For this case, we find the optimal lot sizes for the production of new and for the recovery of returned products and also the optimal number of remanufacturing setup.

The upper part of Figure 3 shows the evolution of the recoverable stock while the lower part of this figure gives the evolution of the serviceable inventory. The per-cycle cost for recoverable items consists of the following four terms:

(i) set-up cost for recovery process per cycle, $n_{1} R$,

(ii) inventory holding cost for triangle of type (a) in Figure 3, $h t U / 2=h r t^{2} / 2$,

(iii) inventory holding cost for trapezoid $(b)$ in Figure $4, h\left[2 U-(p-r) t_{1}\right] t_{1} / 2$, 
(iv) inventory holding cost for $n_{1}-1$ pentagons of type (c) in Figure 4

$$
\begin{aligned}
\sum_{i=1}^{n_{1}-1} \frac{h}{2} & {\left[(2 i-1)(p-r) t_{1}^{2}+[2 i(p-r)-2(i-1) r] t_{1} t_{2}-(2 i-1) r t_{2}^{2}\right] } \\
& =\frac{h(p-r) t_{1}^{2}\left(n_{1}-1\right)^{2}}{2}+\frac{h(p-r) t_{1} t_{2} n_{1}\left(n_{1}-1\right)}{2}-\frac{h r t_{1} t_{2}\left(n_{1}-1\right)\left(n_{1}-2\right)}{2}-\frac{h r t_{2}^{2}\left(n_{1}-1\right)^{2}}{2} .
\end{aligned}
$$

The per-cycle cost for serviceable products consists of the set-up cost per production lot, the inventory holding cost, and the backordering cost. The per-cycle set-up production cost is $S$. The inventory holding cost and the backordering cost can be calculated by the following three terms:

(i) inventory holding cost for triangle of type $(e)$ in Figure $4,(H \overline{F D} y) / 2=H d(s-$ d) $y^{2} / 2 s$,

(ii) inventory holding cost for $n_{1}$ triangles of type $(g)$ in Figure $4, n_{1} H d(p-$ d) $\left(t_{1}+t_{2}\right)^{2} / 2 p$,

(iii) backordering cost for triangle of type $(f)$ in Figure $4, B\left(Q_{p}-V\right) x / 2=B d(s-$ d) $x^{2} / 2 s$.

The total cost per cycle for this case is given as

$$
\begin{aligned}
\mathrm{TC}\left(x, y, n_{1}\right)= & n_{1} R+S+\frac{h r t^{2}}{2}+\frac{H d(s-d) y^{2}}{2 s}+\frac{B d(s-d) x^{2}}{2 s}+\frac{h\left[2 U-(p-r) t_{1}\right] t_{1}}{2} \\
& +\sum_{i=1}^{n_{1}-1} \frac{h}{2}\left[(2 i-1)(p-r) t_{1}^{2}+[2 i(p-r)-2(i-1) r] t_{1} t_{2}-(2 i-1) r t_{2}^{2}\right] \\
& +\frac{n_{1} H\left(t_{1}+t_{2}\right)(p-d) t_{1}}{2},
\end{aligned}
$$

and dividing by the cycle length $T=d(x+y) /(d-r)$, we obtain the total cost per unit of time:

$$
\begin{aligned}
\operatorname{UTC}\left(x, y, n_{1}\right)= & \frac{n_{1} R(d-r)}{d(x+y)}+\frac{S(d-r)}{d(x+y)}+\frac{B(s-d)(d-r) x^{2}}{2 s(x+y)}+\frac{H(s-d)(d-r) y^{2}}{2 s(x+y)} \\
& +\frac{h r^{2}(p-d)(x+y)}{2 n_{1} p(d-r)}+\frac{H r^{2}(p-d)(x+y)}{2 n_{1} p(d-r)}+\frac{h r(x+y)}{2} .
\end{aligned}
$$

In this function, we again make the transformation $x /(x+y)=k$ and we get the result of

$$
\operatorname{UTC}\left(x, k, n_{1}\right)=c_{1} \frac{k}{x}+c_{2} \frac{x}{k}+c_{3} x k-c_{4} x, \quad x \in(0, \infty), k \in(0,1], n_{1}=1,2,3, \ldots,
$$


where for this case

$$
\begin{gathered}
c_{1}=\frac{n_{1} R(d-r)}{d}+\frac{S(d-r)}{d}>0 \\
c_{2}=\frac{r^{2}(p-d)(H+h)}{2 n_{1} p(d-r)}+\frac{r h}{2}+\frac{(s-d)(d-r) H}{2 s}>0 \\
c_{3}=\frac{(s-d)(d-r)(H+B)}{2 s}>0 \\
c_{4}=\frac{(s-d)(d-r) H}{s}>0 .
\end{gathered}
$$

The problem now is

$$
\min _{x, k, n_{1}} \operatorname{UTC}\left(x, k, n_{1}\right) \text {. }
$$

Following the procedure used in Sections 3 and 4, the optimal values of $k$ and $x$ are

$$
\begin{gathered}
k^{*}=\frac{c_{4}}{2 c_{3}}=\frac{H}{H+B^{\prime}} \\
x^{*}=c_{4} \sqrt{\frac{c_{1}}{c_{3}\left(4 c_{2} c_{3}-c_{4}^{2}\right)}} .
\end{gathered}
$$

The Hessian matrix of $\operatorname{UTC}\left(x, k, n_{1}\right)$ at the point $\left(k^{*}, x^{*}\right)$ is positive definite and so this point gives the minimum. Substituting (5.7) into (5.4) yields

$$
\operatorname{UTC}\left(x^{*}, k^{*}, n_{1}\right)=f\left(n_{1}\right)=\sqrt{\frac{c_{1}\left(4 c_{2} c_{3}-c_{4}^{2}\right)}{c_{3}}}=\sqrt{a_{1} b_{1}+a_{2} b_{2}+a_{2} b_{1} n_{1}+\frac{a_{1} b_{2}}{n_{1}}}
$$

where

$$
\begin{gathered}
a_{1}=\frac{r^{2}(p-d)(s-d)(H+B)(H+h)}{p s}>0, \\
a_{2}=\frac{(s-d)(d-r)}{s}\left[\frac{(s-d) H B(d-r)}{s}+r h(H+B)\right]>0 \\
b_{1}=\frac{2 s R}{d(s-d)(B+H)}>0 \\
b_{2}=\frac{2 s S}{d(s-d)(B+H)}>0 \\
L=4 c_{2} c_{3}-c_{4}^{2}=\frac{a_{1}}{n_{1}}+a_{2}>0 .
\end{gathered}
$$


Table 1: A total cost comparison of the policies with and without backlogging.

\begin{tabular}{lccc}
\hline Approach & Optimal policy & Total cost without backlogging & Total cost with backlogging \\
\hline General & $P\left(1, n_{2}^{*}=1\right)$ & 536,656 & 530,659 \\
Koh & $P\left(n_{1}^{*}=3,1\right)$ & 473,286 & 463,724 \\
Nahmias & $P\left(n_{1}^{*}=6,1\right)$ & 386,437 & 369,504 \\
\hline
\end{tabular}

Using the difference function as in Section 3, the optimal $n_{1}^{*}$ satisfies the double inequality

$$
n_{1}^{*}\left(n_{1}^{*}-1\right)<\frac{a_{1} b_{2}}{a_{2} b_{1}} \leq n_{1}^{*}\left(n_{1}^{*}+1\right), \quad n_{1}^{*} \geq 2
$$

In the case that $n_{1}^{*}\left(n_{1}^{*}+1\right)=a_{1} b_{2} / a_{2} b_{1}$, we have two equivalent solutions (same cost). The optimal lot sizes for this class of policies are

$$
\begin{gathered}
Q_{p}=d\left(x^{*}+y^{*}\right), \\
Q_{r}=\frac{d r\left(x^{*}+y^{*}\right)}{n_{1}^{*}(d-r)} .
\end{gathered}
$$

\section{Numerical Example}

The numerical example is used to highlight the application of the results obtained in previous sections and to contact a comparison between the three models. The data are as follows: $d=1000, r=800, s=5000, p=3000, S=20, R=5, h=2, H=10, B=15$.

First, we consider policies of type $P\left(1, n_{2}\right)$. From (3.23), we get that $n_{2}^{*}=1$. Using (3.18), we take that $k^{*}=0.4$ and $x^{*}=0.0075$, and since $x /(x+y)=k$, we have that $y^{*}=$ $x^{*}\left(1-k^{*}\right) / k^{*}=0.0188$. Using (3.24), we get $Q_{p}=26.3$ and $Q_{r}=105.2$. The corresponding total cost is $\operatorname{UTC}\left(x^{*}, k^{*}, n_{2}=1\right)=530.66$. Next, we consider $P\left(n_{1}, 1\right)$ under Koh's approach. From (4.20), we get that $n_{1}^{*}=3$. Using (4.15) and (4.16), we take that $k^{*}=0.109, x^{*}=0.0121$, and since $x /(x+y)=k$, we have that $y^{*}=x^{*}\left(1-k^{*}\right) / k^{*}=0.0989$. Using (4.21), we get $Q_{p}=30.28$ and $Q_{r}=40.36$. The corresponding total cost is $\operatorname{UTC}\left(x^{*}, k^{*}, n_{1}=3\right)=463.724$. Now, we consider $P\left(n_{1}, 1\right)$ under Nahmias' approach. From (5.10), we get that $n_{1}^{*}=6$. Using (5.7), we take that $k^{*}=0.4, x^{*}=0.0217$, and since $x /(x+y)=k$, we have that $y^{*}=x^{*}(1-$ $\left.k^{*}\right) / k^{*}=0.0326$. Using (5.11), we get $Q_{p}=54.3$ and $Q_{r}=36.2$. The corresponding total cost is $\operatorname{UTC}\left(x^{*}, k^{*}, n_{1}=6\right)=369.504$. From the above three policies, we see that the $P\left(n_{1}=6,1\right)$ under Nahmias' approach has lower cost and so it is preferable.

The numerical results given in Table 1 reveal that the models of this paper are cost efficient, compared to corresponding ones without backlogging. This evidence is prevailing to all numerical tests done. So, allowing backlogging can lead to improvement and reduce the cost of recovery systems.

\section{Conclusion and Proposals for Further Research}

In this paper, we analyzed an inventory system with product returns, where remanufacturing is an alternative to manufacturing. Used products returned from customers are kept in the 
recoverable inventory, until the time at which recovery process starts. It is assumed that the constant demand rate can be satisfied by newly produced items and by recovered ones and excess demand is backlogged. The so-arising models were studied within two classes of policies, namely, policies of type $P\left(n_{1}, 1\right)$, with one production lot for new products and at least one recovery setup, and policies of type $P\left(1, n_{2}\right)$, with one recovery set up and at least one production lot. The approaches by Nahmias and Rivera [6] and Koh et al. [8] were adopted in the class of policy $P\left(n_{1}, 1\right)$. These approaches differ only in the time at which recovery process starts. For the above $P\left(1, n_{2}\right)$ and $P\left(n_{1}, 1\right)$ types of policies, a simple procedure that leads to the optimal $n_{1}^{*}, n_{2}^{*}$ values and to the optimal lot sizes was developed.

The results of this paper may be extended to the following cases: allow a variable number of set up on both processes, that is, recovery and production. The solution of such a model will give the global optimal policy for this type of problem. Introducing variable demand and return rates, possible random ones or deterministic but dynamic, makes the model more sensible, although this extremely complicates its analysis. Another way to generalize this model is to ask for quality of the products bought back and to decide the type of the recovery, according to the quality.

\section{Appendix}

\section{Checking the Conditions for the Minimum of $\operatorname{UTC}\left(x, k, n_{i}\right), i=1,2$}

For convenience, let us set UTC $\left(x, k, n_{i}\right)=\mathrm{UTC}, i=1,2$. The Hessian matrix of UTC is

$$
H\left(x, k, n_{i}\right)=\left[\begin{array}{cc}
\frac{2 c_{1} k}{x^{3}} & -\frac{c_{1}}{x^{2}}-\frac{c_{2}}{k^{2}}+c_{3} \\
-\frac{c_{1}}{x^{2}}-\frac{c_{2}}{k^{2}}+c_{3} & \frac{2 c_{2} x}{k^{3}}
\end{array}\right] .
$$

If we set $d_{1}\left(x, k, n_{i}\right)$ and $d_{2}\left(x, k, n_{i}\right), i=1,2$, the principal minor determinants of $H\left(x, k, n_{i}\right)$, to ensure that the unique solution given by (3.18) or (4.15), (4.16) or, (5.7) gives the minimum of the function UTC, when $n_{i}, i=1,2$ is fixed, it is sufficient to prove that $d_{1}\left(x^{*}, k^{*}, n_{i}\right)$ and $d_{2}\left(x^{*}, k^{*}, n_{i}\right)$ are positive. Substituting $x^{*}$ and $k^{*}$ into $d_{i}\left(t_{1}{ }^{*}, t_{3}{ }^{*}, k^{*}, n_{1}\right), i=1,2$, and after some calculations we obtain

$$
\begin{gathered}
d_{1}\left(x^{*}, k^{*}, n_{i}\right)=\frac{2 c_{1} k}{x^{3}}=\frac{\left(4 c_{2} c_{3}-c_{4}^{2}\right)}{c_{4}^{2}} \sqrt{\frac{c_{3}\left(4 c_{2} c_{3}-c_{4}^{2}\right)}{c_{1}}}>0, \\
d_{2}\left(x^{*}, k^{*}, n_{i}\right)=\frac{4 c_{1} c_{2}}{x^{2} k^{2}}-\left(-\frac{c_{1}}{x^{2}}-\frac{c_{2}}{k^{2}}+c_{3}\right)^{2}=\frac{4 c_{3}^{2}\left(4 c_{2} c_{3}-c_{4}^{2}\right)}{c_{4}^{2}}>0,
\end{gathered}
$$

since $c_{1}, c_{3}, c_{4}>0$ and $L=4 c_{2} c_{3}-c_{4}^{2}>0$.

\section{Acknowledgment}

The author would like to thank the referee for the valuable comments and suggestions that improved the paper. 


\section{References}

[1] M. P. de Brito, Managing reverse logistics or reversing logistics management, Ph.D. dissertation, Erasmus University, Rotterdam, 2003.

[2] M. C. Thierry, M. Salomon, J. van Numen, and L. van Wassenhove, "Strategic issues in product recovery management," California Management Review, vol. 37, no. 2, pp. 114-135, 1995.

[3] M. Fleischmann, J. M. Bloemhof-Ruwaard, R. Dekker, E. van der Laan, J. A. E. E. van Nunen, and L. N. van Wassenhove, "Quantitative models for reverse logistics: a review," European Journal of Operational Research, vol. 103, no. 1, pp. 1-17, 1997.

[4] V. D. R. Guide Jr. and R. Srivastava, "Repairable inventory theory: models and applications," European Journal of Operational Research, vol. 102, no. 1, pp. 1-20, 1997.

[5] D. A. Schrady, "A deterministic inventory model for repairable items," Naval Research Logistics Quarterly, vol. 14, no. 3, pp. 391-398, 1967.

[6] S. Nahmias and H. Rivera, "Deterministic model for a repairable item inventory system with a finite repair rate," International Journal of Production Research, vol. 17, no. 3, pp. 215-221, 1979.

[7] M. C. Mabini, L. M. Pintelon, and L. F. Gelders, "EOQ type formulations for controlling repairable inventories," International Journal of Production Economics, vol. 28, no. 1, pp. 21-33, 1992.

[8] S.-G. Koh, H. Hwang, K.-I. Sohn, and C.-S. Ko, “An optimal ordering and recovery policy for reusable items," Computers and Industrial Engineering, vol. 43, no. 1-2, pp. 59-73, 2002.

[9] K. Richter, "The EOQ repair and waste disposal model with variable setup numbers," European Journal of Operational Research, vol. 95, no. 2, pp. 313-324, 1996.

[10] K. Richter, "The extended EOQ repair and waste disposal model," International Journal of Production Economics, vol. 45, no. 1-3, pp. 443-447, 1996.

[11] K. Richter, "Pure and mixed strategies for the EOQ repair and waste disposal problem," OR Spectrum, vol. 19, no. 2, pp. 123-129, 1997.

[12] K. Richter and I. Dobos, "Analysis of the EOQ repair and waste disposal problem with integer setup numbers," International Journal of Production Economics, vol. 59, no. 1-3, pp. 463-467, 1999.

[13] K. Richter and I. Dobos, "Production-inventory control in an EOQ-type reverse logistics system," in Supply Chain Management and Reverse Logistics, H. Dyckhoff, R. Lackes, and J. Reese, Eds., pp. 139-160, Springer, Berlin, Germany, 2004.

[14] I. Dobos and K. Richter, "The integer EOQ repair and waste disposal model—further analysis," Central European Journal of Operations Research, vol. 8, no. 2, pp. 173-194, 2000.

[15] I. Dobos and K. Richter, "An extended production/recycling model with stationary demand and return rates," International Journal of Production Economics, vol. 90, no. 3, pp. 311-323, 2004.

[16] I. Dobos and K. Richter, "A production/recycling model with quality consideration," International Journal of Production Economics, vol. 104, no. 2, pp. 571-579, 2006.

[17] R. H. Teunter, "Economic ordering quantities for recoverable item inventory systems," Naval Research Logistics, vol. 48, no. 6, pp. 484-495, 2001.

[18] R. Teunter, "Lot-sizing for inventory systems with product recovery," Computers $\mathcal{E}$ Industrial Engineering, vol. 46, no. 3, pp. 431-441, 2004.

[19] D.-W. Choi, H. Hwang, and S.-G. Koh, "A generalized ordering and recovery policy for reusable items," European Journal of Operational Research, vol. 182, no. 2, pp. 764-774, 2007.

[20] S. Minner and G. Lindner, "Lot sizing decisions in product recovery management," in Reverse Logistics-Quantitative Models for Closed-Loop Supply Chains, R. Dekker, M. Fleischmann, K. Inderfurth, and L. N. van Wassenhove, Eds., pp. 157-179, Springer, Berlin, Germany, 2004.

[21] A. M. A. El Saadany and M. Y. Jaber, "The EOQ repair and waste disposal model with switching costs," Computers \& Industrial Engineering, vol. 55, no. 1, pp. 219-233, 2008.

[22] M. Y. Jaber and M. A. Rosen, "The economic order quantity repair and waste disposal model with entropy cost," European Journal of Operational Research, vol. 188, no. 1, pp. 109-120, 2008.

[23] M. Y. Jaber and A. M. A. El Saadany, "The production, remanufacture and waste disposal model with lost sales," International Journal of Production Economics, vol. 120, no. 1, pp. 115-124, 2009.

[24] K. F. Yuan and Y. Gao, "Inventory decision-making models for a closed-loop supply chain system," International Journal of Production Research, vol. 48, no. 20, pp. 6155-6187, 2010.

[25] S. Minner and R. Kleber, "Optimal control of production and remanufacturing in a simple recovery model with linear cost functions," OR Spektrum, vol. 23, no. 1, pp. 3-24, 2001.

[26] G. P. Kiesmüller, S. Minner, and R. Kleber, "Optimal control of a one product recovery system with backlogging," IMA Journal of Mathematics Applied in Business and Industry, vol. 11, no. 3, pp. 189-207, 2000 . 


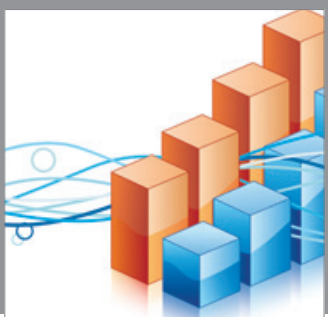

Advances in

Operations Research

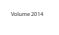

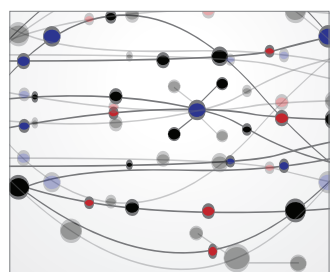

\section{The Scientific} World Journal
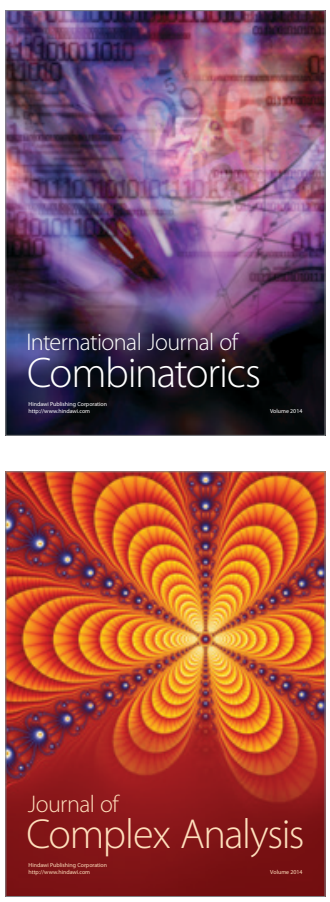

International Journal of

Mathematics and

Mathematical

Sciences
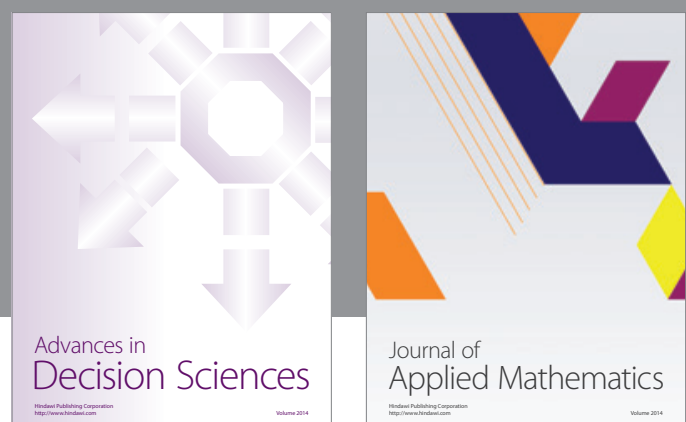

Journal of

Applied Mathematics
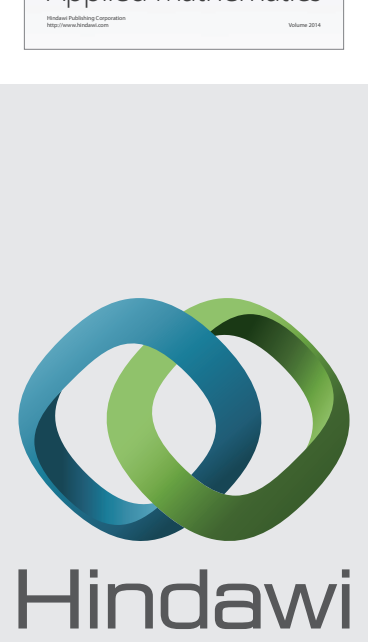

Submit your manuscripts at http://www.hindawi.com
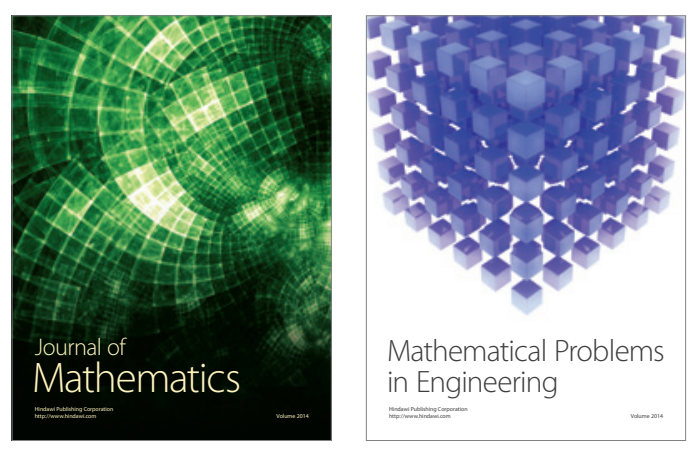

Mathematical Problems in Engineering
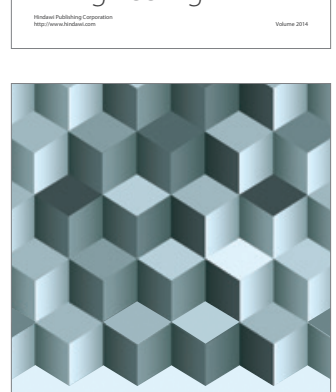

Journal of

Function Spaces
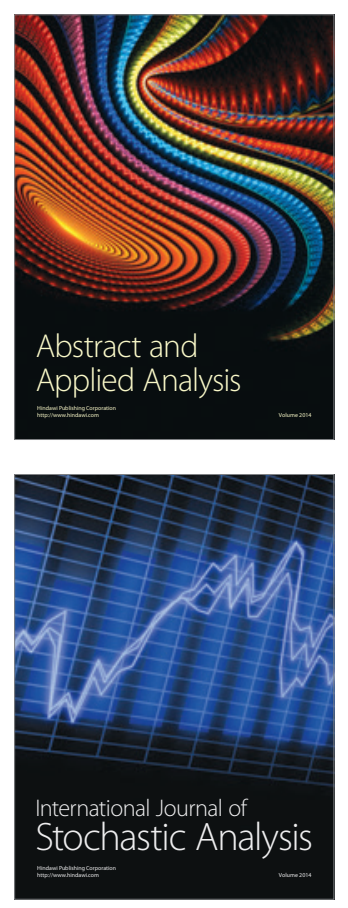

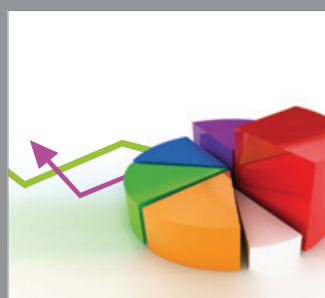

ournal of

Probability and Statistics

Promensencen
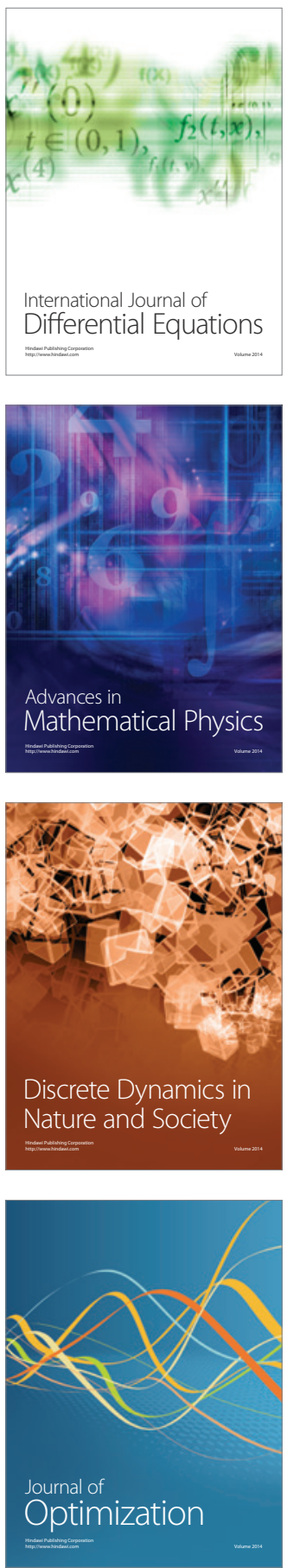